\title{
The Effect of Interior Planting on Health and Discomfort among Workers and School Children
}

Tove Fjeld

ADDITIONAL INDEX WORDS. benefits of plants, foliage plants, fluorescent lighting, full-spectrum lighting, human-horticulture relationships, human issues in horticulture, human well-being, mucus membrane symptoms, neuropsychological symptoms, people-plant interactions

Summary. Plants are widely used in building environments; however, studies reporting the health and discomfort symptoms of people in response to indoor foliage plants are few. The objective of the presented studies was to assess the effect of foliage plants or a combination of foliage plants and full-spectrum fluorescent lamps on self-reported health and discomfort complaints in three different work environments: an office building, an X-ray department in a N orwegian hospital, and a junior high school. $\mathrm{H}$ ealth and discomfort symptoms were found to be $21 \%$ to $25 \%$ lower during the period when subjects had plants or plants and full-spectrum lighting present compared to a period without plants. N europsychological symptoms, such as fatigue and headache, and mucous membrane symptoms, such as dry and hoarse throat, seemed to be more affected by the treatments than skin symptoms, such as itching skin.

$\mathrm{P}$ lants are widely used in building environments; however, studies reporting the way people respond to indoor foliage plants regarding human health and discomfort symptoms are few. D uring the 1980s, laboratory studies reported that plants may reduce the level of air contaminants, including formaldehyde, benzene, trichloroethylene, carbon monoxide and nitrogen dioxide (Wolverton et al., 1989). O ther studies have shown that the well-being of people, as well as their psychological and physiological stress levels, may be appreciably influenced by the surroundings; it appears that vistas dominated by vegetation may give relief from stress (U Irich, 1979; U Irich et al., 1993; U Irich and Parsons, 1992). O $n$ the other hand, it seems that health and discomfort problems are increasing among people that work in modern buildings, possibly due to new building materials and increased emphasis on energy saving (Skov et al., 1990). It is therefore relevant to investigate to what extent indoor plantings affect the well-being of persons who are working in modern buildings. The objective of this work was to assess whether indoor foliage plants used for decoration (Study 1) or a combination of plants and fullspectrum daylight fluorescent light (Study 2 and Study 3) affect selfreported human health and discomfort symptoms.

Former professor, D epartment of $\mathrm{H}$ orticulture and C rop Sciences, A gricultural U niversity of N orway. C urrent address: $\mathrm{N}$ ordbyvn. 38, 1406 Ski, N orway.

The author appreciates the financial support given by Flower Council of $\mathrm{H}$ olland, Statoil AS, N orwegian Growers Association, Gartnerhallen AS, and Blomsterringen EngrosAS. The cost of publishing this paper was defrayed in part by the payment of page charges. U nder postal regulations, this paper therefore must be hereby marked adverti sement solely to indicate this fact. 


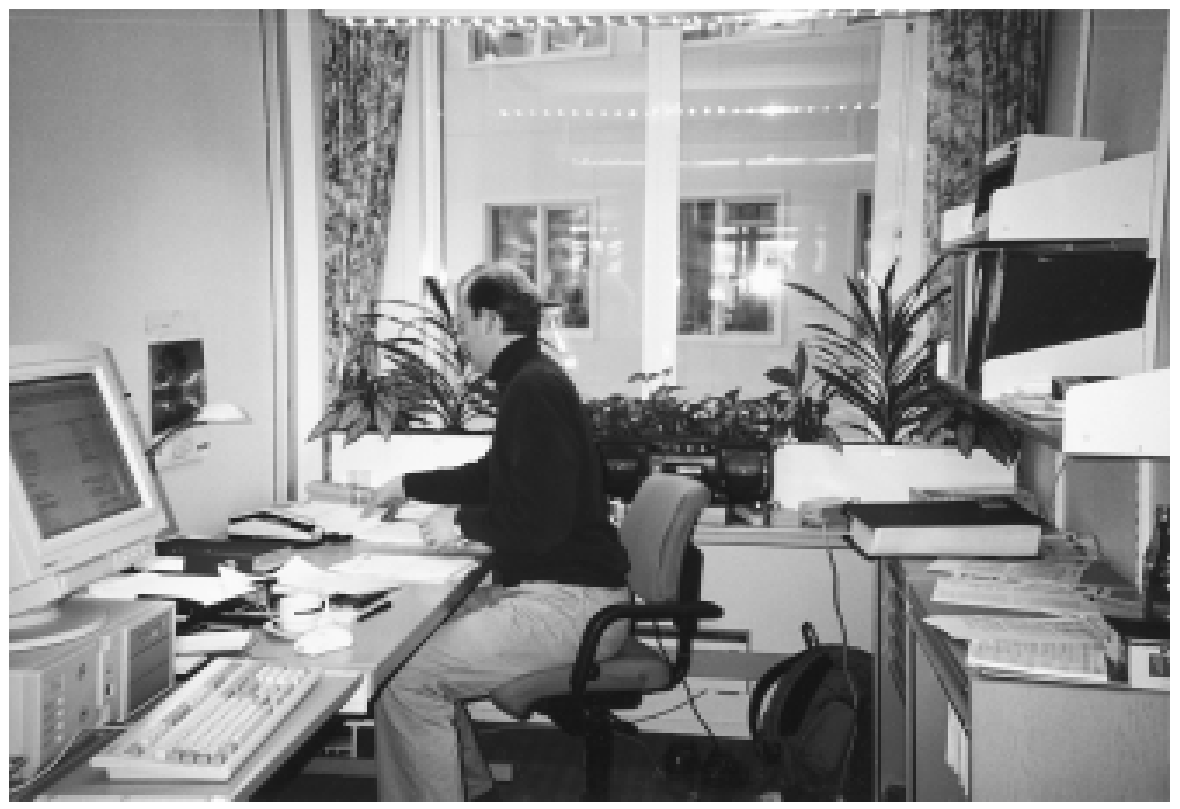

Fig. 1. In the office experiment in Study 1, three self-watering containers filled with common interior plants were placed on the window bench during the intervention with plants. I n addition, a terracotta container with plants stood in the back corner of the office (not shown in the photograph).

\section{Methods}

STUDY 1: EFFECTS OF INDOOR FOLIAGE PLANTS ON HEALTH AND DISCOMFORT SYMPTOMS AMONG OFFICE WORKERS. A crossover study with randomized period order, with one period with plants in the office and one period without plants in the office, was conducted among 51 office workers (27 males and 24 females). The plant intervention consisted of 13 common foliage plants that were placed in three selfwatering containerson awindow bench and in a terracotta container in the back corner of the office (Fig. 1). The planters contained golden evergreen (A glaonema commutatum Schott.), striped dragonpalm (D racaena deremensis Engl.), golden pothos (Epipremnum aureum ( Lind. \& André) Bunting), and heartleaf philodendron ( $P$ hilodendron scandens $K$. Koch and Sello var. oxycardium (Schott) Bunting). Theterracottacontainer was filled with a $175 \mathrm{~cm}$ ( $6 \mathrm{ft}$ ) corn plant [D racaena fragrans (L.) Ker-Gawl.] 'J anet C raig' and heartleaf philodendron. All participantsworked in single office rooms that were identical, with a floor area of $10 \mathrm{~m}^{2}$ (108 $\mathrm{ft}^{2}$ ) and a window covering most of the outer wall.

The participants completed a questionnaire every second week during two periods: 3 months in Spring Full spectrum lighting was also added. problems). Demographic data were collected.

STUdY 2: EFFECTS OF INDOOR FOLIAGE PLANTS AND FULL-SPECTRUM FLUORESCENT LIGHT ON HEALTH AND DISCOMFORT SYMPTOMS AMONG WORKERS IN A HOSPITAL RADIOLOGY DEPARTMENT. The location for this study was a room of about $80 \mathrm{~m}^{2}\left(860 \mathrm{ft}^{2}\right)$ with no windows or natural light. The room was used for the examination of X-ray films. Baselineinformation regarding 12 different health and discomfort symptoms was sampled among 48 employees at a hospital radiology department (37 females, 11 males). The information was collected by means of the same questionnaire used in Study 1 four times during September and O ctober 1997.

I $n$ the middle of $\mathrm{N}$ ovember 1997 , the indoor environment of the room was changed as follows: 23 containers with one or more commonly used indoor foliage plants were placed into the room and light sources in the ceiling and in the film viewers were changed to full-spectrum fluorescent light (True-L itefrom D uro-T est) (Fig. 2 ). The plants consisted of four ming aralia (Polyscias fruti cosa (L .) H arms) $[175 \mathrm{~cm}(6 \mathrm{ft})]$, as well as the same plant species that were used in the office study (Study 1). Sampling of health and discomfort information, via the samequestionnaire, continued five times during the period from $\mathrm{N}$ ovem-

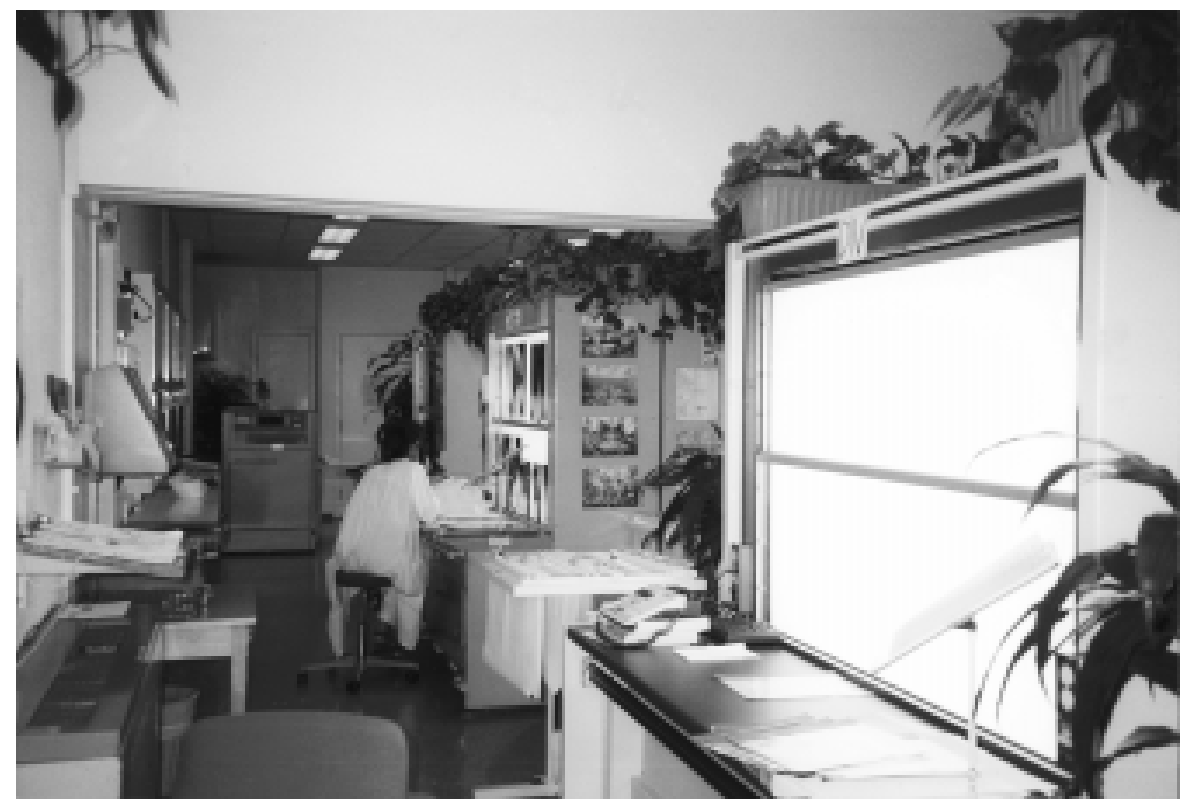

Fig. 2. The radiology department location (Study 2) during the intervention received 23 plant containers, both on top of the film viewers and on the floor. 


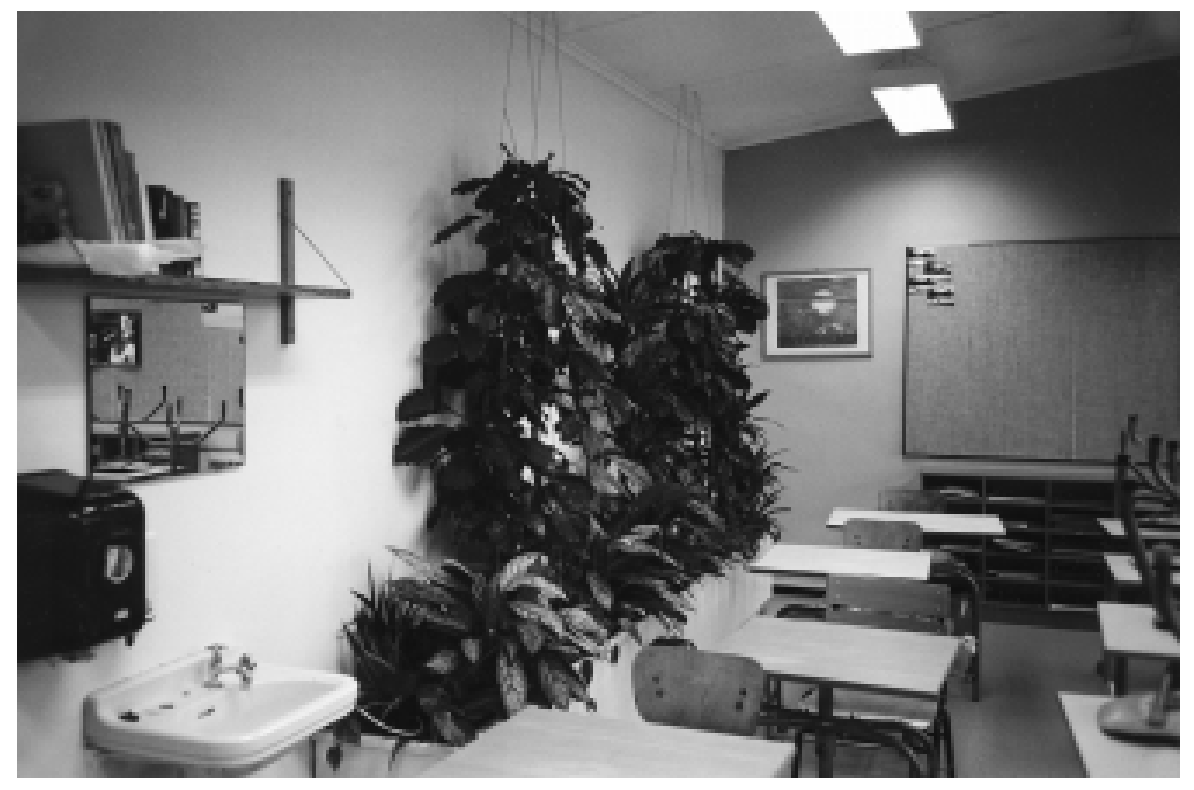

Fig. 3. T he biological classroom (Study 3) was created by adding foliage plants in a bioprocess system and by using full-spectrum lighting.

ber 1997 to February 1998. Demographicsand information on how much of the workday each employee spent in the room were also gathered. All together 51 air samples were collected before and after intervention, in order to analyze possible changes in content of fungi in the air. Air samples were analyzed by the N orwegian Institute for $\mathrm{G}$ eneral $\mathrm{H}$ ealth, $\mathrm{O}$ slo.

STUDY 3: EFFECTS OF INDOOR FOLIAGE PLANTS AND FULL-SPECTRUM FLUORESCENT LIGHT ON HEALTH AND DISCOMFORT SYMPTOMS AMONG PUPILS IN A JUNIOR HIGH SCHOOL. Significant problems with the indoor air quality in the classrooms were the background for establishing thisstudyin ajunior high school $15 \mathrm{~km}$ (9.3 miles) southwest of O slo, N orway. I I February 1997, threeclassrooms were planted with tropical, indoor plants in a bioprocess system (indoor air flows through the soil/ root-zone), the light sources were changed to full-spectrum fluorescent lamps (True-Lite from Duro-T est), and the irradiance level was increased to 700 to 800 lux. These were referred to as biological classrooms (Fig. 3). Thefollowing plantswereused: golden evergreen, striped dragonpalm, corn plant, golden pothos, heartleaf philodendron, and javan grape (T etrastigma Planch.).

In February 1998, a pilot survey wasconducted among pupilsand teachers, by means of four different questionnaires. I nformation regarding wellbeing and health and discomfort symp- toms, as well as information regarding how the pupils perceived their indoor environment (semantic information), was sampled among the pupils using the three biological classrooms ( $n=$ 61). A control group was established of pupils from three classes using ordinary classrooms ( $n=59)$. Ages of the pupils were 14 to 16 years.

Statistical analyses. Since most of the subjects in Study 1 and 2 did not fill in the questionnaire at all sampling dates (due to traveling, illness etc.), a mean score was calculated for each person for every symptom in each of the two periods (Spring 1995 and 1996 for Study 1 and before and after intervention for Study 2). The statistical analysis is based on these mean scores, together with the mean sum score (summarized for all 12 symptoms).

A two-sided Wilcoxon signedrank test was used to decide if a mean difference between the periods or locations with and without plants was statistically significant. In the crossover study, analysis was conducted to check carry-over effects that might destroy the crossover design. N o carryover effects were seen in any of the symptom scores. In the radiology department study and the school study, parallel-group analysis was conducted by using a two-sided Wilcoxon rank sum test to check single symptoms. For the semantic information (Study 3 ), simple means of the characteristics were calculated.

\section{Results}

Study 1. It was found that the mean score sum, as a mean of 12 symptoms, was $23 \%$ lower during the period when the participants were exposed to plants in their offices compared to the period without plants. The mean score sum was 7.1 during the period without plants, while it was 5.6 during the period with plants $(P=$ 0.002 ). Complaints regarding cough and fatigue were reduced by $37 \%$ and $30 \%$, respectively, if the offices contained plants, while the self-reported level of dry or hoarse throat and dry or flushed facial skin each decreased about 23\%after intervention ( $T$ able 1 ). If the symptoms are grouped by the body's responses (Fjeld et al., 1998), a significant reduction was obtained in neuropsychological symptoms (fatigue, feeling heavy-headed, headache, dizziness, and concentration problems) and in mucous membrane symptoms (itching or irritation of the eyes; irritated, running, or stuffy nose; dry or hoarse throat; and cough), while skin symptoms (dry or flushed facial skin; scaling or itching scalp or ears; and hands with dry, itching, or red skin) seemed to be unaffected by the plant intervention.

The responses from the participants also indicate that green plantsin the office were regarded as a positive element for feelings of well-being, with $82 \%$ of the participants agreeing to the statement "I feel morecomfortableifI haveplantsin my office" and 82\%agreeing to the statement "I would like to have plantsin my officein the future" (Table 2).

Study 2. A 25\% decrease in complaints was observed after changing the interior environment of a hospital radiology department by adding plants and full-spectrum lights. The mean score sum of 12 complaints was 9.0 before intervention and 6.7 after intervention ( $P=0.0001)$. $\mathrm{H}$ ighly significant effects were found in the following specific symptoms: fatigue; feeling heavy-headed; headache; dry or hoarse throat; and hands with dry, itching, or red skin (T able 3 ). When subjects were grouped according to how much daily work took place in the study location, a34\%decrease in complaintswasfound among those who spent most of their day in the room, compared to $21 \%$ among those working about half of each day there and $17 \%$ among those working less than half of the day in the 
Table 1. Effects of plant intervention on mean scores of 12 self-reported health and discomfort symptoms among office workers $(n=51)$. Scores indicate symptoms present on the day the questionnaire was filled out.

\begin{tabular}{|c|c|c|c|c|}
\hline Symptoms & $\begin{array}{c}\text { Score }^{2} \\
\text { without } \\
\text { plants }\end{array}$ & $\begin{array}{l}\text { Score }^{2} \\
\text { with } \\
\text { plants }\end{array}$ & $\begin{array}{l}\text { Reduction if } \\
\text { plants are } \\
\text { present (\%) }\end{array}$ & $\mathbf{P}$ \\
\hline \multicolumn{5}{|l|}{ N europsychological symptoms } \\
\hline Fatigue & 0.82 & 0.58 & 30 & 0.001 \\
\hline Feeling heavy-headed & 0.71 & 0.58 & 18 & 0.055 \\
\hline $\mathrm{H}$ eadache & 0.33 & 0.27 & 18 & 0.25 \\
\hline Dizziness/ nausea & 0.27 & 0.22 & 18 & 0.34 \\
\hline Concentration problems & 0.50 & 0.42 & 16 & 0.22 \\
\hline \multicolumn{5}{|l|}{ M ucus membrane symptoms } \\
\hline Itching or irritation of the eyes & 0.70 & 0.59 & 16 & 0.14 \\
\hline I rritated, running, or stuffy nose & 0.60 & 0.43 & 28 & 0.081 \\
\hline D ry or hoarse throat & 0.83 & 0.62 & 24 & 0.022 \\
\hline Cough & 0.38 & 0.24 & 37 & 0.020 \\
\hline \multicolumn{5}{|l|}{ Skin symptoms } \\
\hline D ry or flushed facial skin & 0.88 & 0.68 & 23 & 0.044 \\
\hline Scaling or itching scalp or ears & 0.56 & 0.51 & 9 & 0.38 \\
\hline $\mathrm{H}$ ands with dry, itching, or red skin & 0.52 & 0.50 & 4 & 0.76 \\
\hline
\end{tabular}

${ }^{2}$ Based on a scale of $0=$ no symptoms, $1=$ minor symptoms, $2=$ moderate symptoms, $3=$ severe symptoms.

Table 2. D istribution of answers obtained from 51 office workers in response to the question "To what extent do you agree with the following statements?"

\begin{tabular}{lccccc}
\hline & \multicolumn{4}{c}{ Answers (distribution in \%) } \\
\cline { 2 - 6 } Statement & $\begin{array}{c}\text { I agree } \\
\text { strongly }\end{array}$ & $\begin{array}{c}\text { I agree } \\
\text { somewhat }\end{array}$ & $\begin{array}{l}\text { I am } \\
\text { indifferent }\end{array}$ & $\begin{array}{c}\text { I disagree } \\
\text { somewhat }\end{array}$ & $\begin{array}{c}\text { I disagree } \\
\text { strongly }\end{array}$ \\
\hline I feel more comfortable with than without plants in my office & 51 & 31 & 7 & 7 & 4 \\
I feel that the air improves when there are plants in my office & 22 & 24 & 40 & 9 & 4 \\
I would like to have plants in my office in the future & 66 & 16 & 13 & 2 & 2 \\
$\begin{array}{l}\text { The plants used in the project occupied too much of the } \\
\text { workspace around my desk }\end{array}$ & 27 & 29 & 18 & 20 & 6 \\
\hline
\end{tabular}

Table 3. Effects of plant intervention on mean scores of 12 self-reported health and discomfort symptoms among workers in a hospital radiology department $(n=48)$. Scores indicate symptoms present on the day the questionnaire was filled out.

\begin{tabular}{|c|c|c|c|c|}
\hline Symptom & $\begin{array}{l}\text { Score } \\
\text { before } \\
\text { plants }\end{array}$ & $\begin{array}{l}\text { Score }^{2} \\
\text { after } \\
\text { plants }\end{array}$ & $\begin{array}{l}\text { Reduction if } \\
\text { plants are } \\
\text { present (\%) }\end{array}$ & $\mathbf{P}$ \\
\hline \multicolumn{5}{|l|}{ N europsychological symptoms } \\
\hline Fatigue & 1.24 & 0.84 & 32 & 0.001 \\
\hline Feeling heavy-headed & 1.16 & 0.78 & 33 & 0.004 \\
\hline H eadache & 0.72 & 0.40 & 45 & 0.009 \\
\hline Dizziness & 0.20 & 0.15 & 25 & 0.297 \\
\hline Concentration problems & 0.40 & 0.41 & -2.5 & 0.778 \\
\hline \multicolumn{5}{|l|}{ M ucus membrane symptoms } \\
\hline I tching or irritation of the eyes & 0.66 & 0.56 & 15 & 0.298 \\
\hline I rritated, running, or stuffy nose & 0.81 & 0.72 & 11 & 0.589 \\
\hline D ry or hoarse throat & 0.97 & 0.67 & 31 & 0.0009 \\
\hline Cough & 0.34 & 0.21 & 38 & 0.84 \\
\hline \multicolumn{5}{|l|}{ Skin symptoms } \\
\hline D ry or flushed facial skin & 0.79 & 0.70 & 11 & 0.146 \\
\hline Scaling or itching scalp or ears & 0.37 & 0.30 & 19 & 0.256 \\
\hline $\mathrm{H}$ ands with dry, itching, or red skin & 1.23 & 0.97 & 21 & 0.0025 \\
\hline
\end{tabular}


T able 4. Mean scores of 10 discomfort symptoms reported by pupils in biological classrooms $(n=61)$ and traditional classrooms $(n=59)$ in response to the following question: " $\mathrm{H}$ ave you been bothered by any of the following symptoms during the last week?

\begin{tabular}{lccc}
\hline Symptom & $\begin{array}{c}\text { Score }{ }^{2} \text { in } \\
\text { biological } \\
\text { classroom }\end{array}$ & $\begin{array}{c}\text { Score } \text { in } \\
\text { traditional } \\
\text { classroom }\end{array}$ & $\begin{array}{c}\text { Reduction } \\
\text { in biological } \\
\text { classroom (\%) }\end{array}$ \\
\hline N europsychological symptoms & & & \\
$\quad$ Fatigue & 2.2 & 2.4 & 9 \\
$\quad$ Feeling heavy-headed & 1.6 & 1.9 & 15 \\
$\quad$ H eadache & 0.9 & 1.7 & $37^{*}$ \\
$\quad$ Concentration problems & 1.4 & 1.7 & 16 \\
M ucus membrane symptoms & & & \\
D ry, itching eyes & 1.7 & 1.0 & $30 *$ \\
$\quad$ D ry or hoarse throat & 1.0 & 1.6 & $36 *$ \\
Cough & 2.5 & 1.8 & 17 \\
$\quad$ I have had/ have a cold/ the flu & 1.9 & 2.0 & 4 \\
Skin symptoms & & & \\
$\quad$ D ry or flushed facial skin & 1.1 & 1.5 & 25 \\
$\quad$ H ands with dry, itching, or red skin & 1.0 & 1.3 & 20 \\
$\quad$ Sum of symptom scores & 13.3 & 16.8 & $21^{*}$
\end{tabular}

zBased on a scale of $0=$ no symptoms, $1=$ minor symptoms, $2=$ moderate symptoms, 3 = severe symptoms. ${ }^{*}$ Significant at $\mathrm{P}<0.05$.

room (data not shown). All together 51 air samples were collected before and after intervention, in order to analyze possible changes in content of fungi in the air. No changes in content of fungi or fungi spores were observed after intervention.

StudY 3. T he sum of symptomsor health complaints was $21 \%$ lower among pupils in biological classrooms compared to thosein the control classrooms (Table 4). Complaints regarding headache and dry or hoarse throat were found to be $37 \%$ and $36 \%$ lower, respectively, among pupils in biological classrooms compared to the control (T able 4). No significant differences between pupils in the two types of classrooms were observed regarding symptoms of flu or colds: both groups of pupils seemed to be affected at the same range. In spite of this, complaintsregarding respiratorysymptoms (dry, itching eyes and dry or hoarse throat) and headache were significantly lower in the biological classrooms, indicating less strain induced by the indoor environment.

The results indicated significant changes in the perception of the classrooms due to the intervention: the semantic survey showed that pupils in biological classrooms gave a more positive evaluation of their classrooms, including rating the room as more beautiful, brighter, and more comfortable, compared to thecontrol group (Fig. 4).

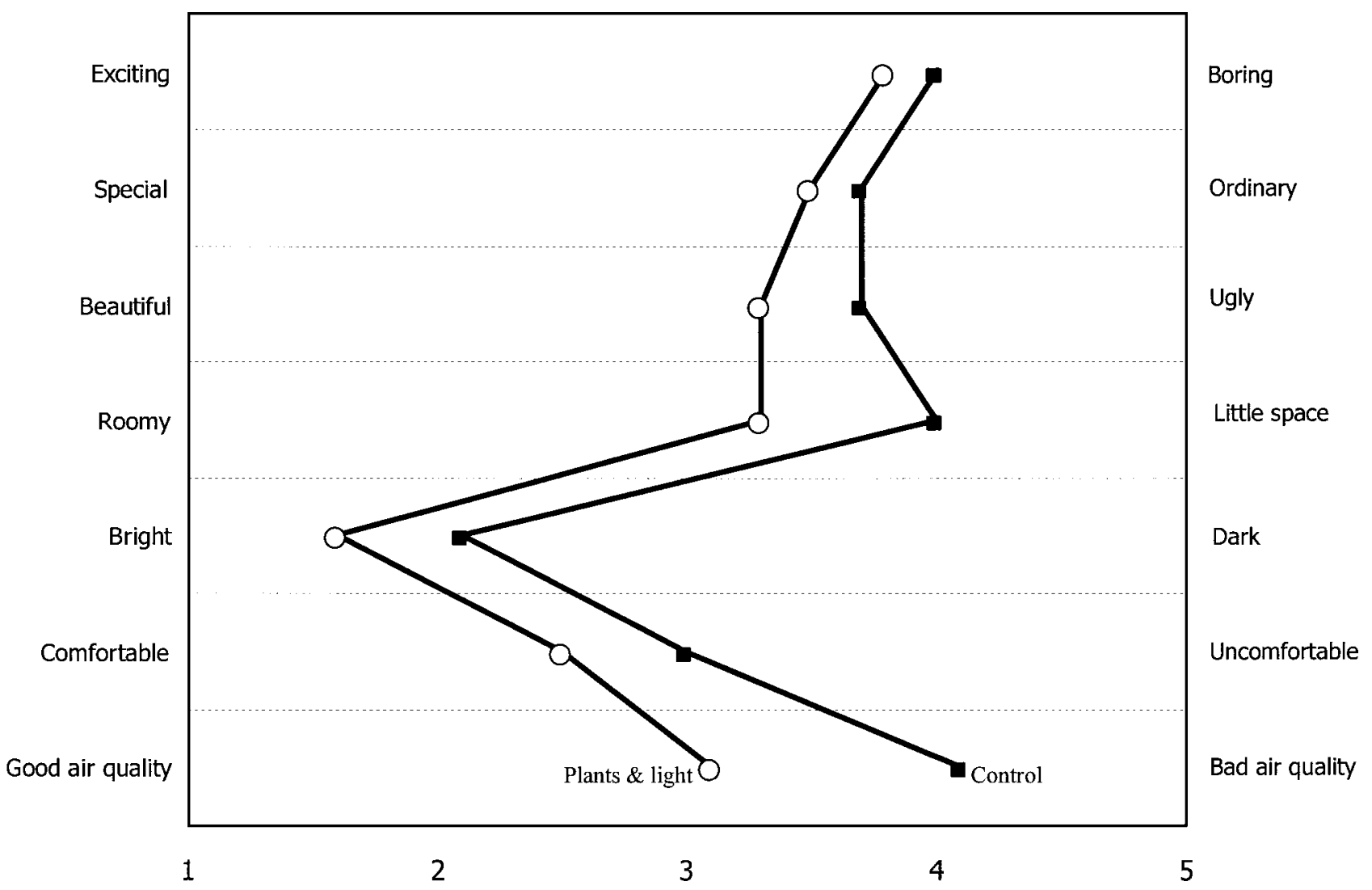

Fig. 4. Distribution of answers on seven different characteristics of the interior classroom environment, presented as semantic pairs. Data given is the mean of 61 pupils using biological classrooms (open circles) and 59 pupils using traditional classrooms (closed squares). Scale ranges from 1 (very similar to the positive characteristic) through 5 (very similar to the negative characteristic). 
Table 5. Comparison of effects of plant intervention on mean scores ${ }^{2}$ of all health and discomfort symptoms in three different studies.

\begin{tabular}{lccc}
\hline $\begin{array}{l}\text { Study } \\
\text { subjects }\end{array}$ & $\begin{array}{c}\text { Score } \\
\text { without } \\
\text { plants }^{2}\end{array}$ & $\begin{array}{c}\text { Score } \\
\text { with } \\
\text { plants }\end{array}$ & $\begin{array}{c}\text { Reduction if } \\
\text { plants are } \\
\text { present (\%) }\end{array}$ \\
\hline Office personnel & 0.59 & 0.47 & 21 \\
Radiology department employees & 0.75 & 0.56 & 25 \\
School children & 1.68 & 1.33 & 21 \\
\hline
\end{tabular}

zBased on a scale of 0 =no symptoms, $1=$ minor symptoms, $2=$ moderate symptoms, 3=severe symptoms. Scores indicate the self-experienced health and discomfort on the day the questionnaire was filled out.

The self-experienced indoor air quality was also reported as better among pupils in the biological classrooms. Although the plants in fact occupied some floor and wall space, neither pupils (Fig. 4) nor teachers (data not shown) seemed to think that the plant system occupied to o much space in the classroom.

Pupilsusing biological classrooms seemed satisfied with the intervention: $69 \%$ evaluated their well-being as better in a biological classroom as compared to an ordinary classroom, and $82 \%$ of thepupilshoped to use biological classrooms in the future (data not shown).

Simple comparison between the THREE STUDIES. The three presented studies were conducted at different locations, at different times, and with different subjects, yet the results were in the same range when it came to the level of reduction of health and discomfort symptoms due to the interventions(Table 5). I n addition, a quite similar trend was found regarding which specific symptoms or symptom groups were affected: neuropsychological symptoms, such as fatigue and headache, and mucousmembraneirritations and irritations of respiratory organs seemed to be affected more than skin symptoms.

In the office study and the radiology department study, analyses were conducted regarding demographics. $\mathrm{N}$ o significant differencesin any of the two studies were found regarding age, gender or smoking habits among the subjects (data not shown).

\section{Discussion}

The present studies strongly suggest that foliage plants and foliage plants in combination with full-spectrum fluo rescent light may appreciably influencehealth and discomfort symptoms. People reported fewer complaintsunder thetreatment conditions than under control conditions. Our findings may have several main explanations: 1) an improvement of air quality by the plants, 2) an increase in general well-being due to the perception of foliage plants, 3) an appreciable influence from establishing a more nature-like indoor light environment, and 4) an effect of increased attention towards the employees.

Earlier studies have shown that commonly used species of ind oor foliage plants may reduce the content of air contaminants. Plants exposed to high levels of chemicals in sealed Plexiglas chambers markedly reduced the concentration of air contaminants in those chambers (Wolverton et al., 1989). These results, however, do not necessarily apply to the office condition, since the removal rate of pollutants by plants is much slower than that of an optimal-functioning ventilation system (L evin, 1992). A minor change in the content of air contaminants might, on the other hand, have a positive influence on the employees' experience of comfort (Forsberg et al., 1997), and thereby result in a lower score on the self-reported health and discomfort symptoms. The symptoms chosen for this study are known to be affected by indoor air quality.

Theplantsmight also increase the air humidity (Lohr, 1992a, 1992b). In buildings with a modern, well-functioning ventilation system, the humidity supplied by the plants would tend to bedistributed throughout thebuilding. It is, however, likely that the microclimate around the plants will have a somewhat higher level of humidity. Particulate matter accumulation has also been found to be lower when plants were present compared to the absence of plants in a room (L ohr and Pearson-M ims, 1996). H ence, thesubjects' perception of the air qualitymight be affected, especially since most of the plants were placed close to the subjects. The effect of plants on the perception of the local air quality may, therefore, be one explanation of our results.

The decreasein health complaints during the period with plants may also be explained by an improvement in well-being. According to U Irich and Parsons (1992), it seems clear that the benefit of viewing vegetation goes far beyond aesthetics and includes not only psychological effects, but al so measurable physiological effects (U Irich, 1981). Relief from stress may be accomplished faster and morecompletely if the setting is dominated by vegetation than if it is an urban one with little or no vegetation (U Irich et al., 1991). It has also been reported that the recovery of patients from surgery may be influenced by the view the patient has through the window, resulting in shorter postoperative stays and fewer postsurgical complications if patients looked out on trees compared to patients who looked out on a brick wall (Ulrich, 1984). A more recent study indicated that living plants might appreciably affect systolic blood pressure and even reaction time on a computerbased productivity task among students (L ohr et al., 1996). This meansthat it is likelythat indoor vegetation may change the indoor environment in such a way that it will correspond better with our psychological or biological capacity, and hence may influence the measurable stress level in the body. When people intuitively express a positive preference towards plants, indoor or outdoor, and thereby tell that their feeling of wellbeing isgood or that theenvironment is nice or more relaxing, they are probably reflecting the interaction between the psychological effect and the physiological response. The second explanation for our findings, hence, may be an increase in general well-being due to the plants.

A change in the light environment might influence both visual and nonvisual effects. Studies on seasonal affective disorder (winter depression) give reason to believe that both the light level and the spectral constitution of light might influence health and well-being-especially symptoms regarding neuropsychological effects (Küller and Lindsten, 1992; $M$ aas et al., 1974; R osenthal et al., 1984). Effects obtained in Study 2 and Study 3 , therefore, might be an interaction of plant effects and light effects.

A nother explanation of our findings may be an effect from increased 
attention ( $\mathrm{H}$ awthorne-effect). An attempt to minimize this effect was performed in the office study by giving the control group the opportunity to have a nature poster on the office wall. In the radiology department study, six of the participants were interviewed 11 months after intervention (Bingen, 1998) to get information on longterm effects. This follow-up clearly indicated that the effects of the changed environment still were of significant impact. The effect of decrease in headache was especially pronounced. Another argument against a strong effect of increased attention is that not all variables investigated showed an effect. Thus, we consider this effect of increased attention to be of minor importance in the present studies.

$\mathrm{N}$ o changes in content of fungi or fungi spores were observed after introducing plants into theindoor environment. This corresponds with earlier results, that have concluded that indoor plantsare not a significant source of microorganisms(Burgeetal., 1982; Rautiala et al., 1999).

O ur studies did not aim to separatepossible factors that were interacting, and hence, were potentially responsible for the results obtained. Therefore, we are not able to quantify the effects due to better air quality from effects due to psychological or stress-reducing responses.

Considered together with documentation from laboratory studies of plant physiology and documentation within the field of environmental psychology, thereshould not beanydoubt regarding the ability of indoor plants to act as an interesting tool in the effort to improve the indoor environment in such a way that it also may affect productivity, work satiffaction, or even sick-leave absence.

From an economic point of view, it should be of great interest to use plants as a work environment asset, since only small investments arenecessary to establish a green indoor environment. In addition and just as important: the personal well-being and the quality of the everyday working situation may be increased for the employees.

\section{Literature cited}

Anderson, K., I. Fagerlund, G. Stridh G, and B. Larsson. 1993. The M M -questionnaires. $A$ tool when solving indoor climate problems. Institut för Miljömedicin, Ö rebro H ospital, Ö rebro, Sweden.

Bingen, M. 1998. Indoor plants-Interviewing employees at a hospital radiology department (in Norwegian). Agr. U niv. N orway, Aas, N orway.

Burge, H.A., W.R. Solomon, and M.L. Muilenber. 1982. Evaluation of indoor plantings as allergen exposure sources. J. Allergy Clin. I mmunol. 70:101-108.

Fjeld, T., B. Veiersted, L. Sandvik, G. Riise, and F. Levy. 1998. The effect of indoor foliage plants on health and discomfort symptoms among office workers. Indoor Built Environ. 7:204-206.

Forsberg, B., N. Stjernberg, and S. Wall. 1997. People can detect poor air quality well below guideline concentrations: $A$ prevalence study of annoyance reactions and air pollution from traffic. O ccup. Environ. M ed. 54:44-48.

Küller, R. and C. Lindsten. 1992. H ealth and behaviour of children in classrooms with and without windows. J. Environ. Psychol. 12:305-317.

Levin, H . 1992. Can house plants solve IAQ problems? I ndoor Air Bul. 2(2):1-5.

Lohr, V.I. 1992a. Research on human issuesin horticulture motivates students to learn science. H ortT echnology 2:257-259.

Lohr, V.I. 1992b. The contribution of interior plants to relative humidity in an office, p. 117-119. In: D. Relf (ed.). The role of horticulture in human well-being and social development. Timber Press, Portland, Ore.

Lohr, V.I. and C.H. Pearson-M ims. 1996. Particulate matter accumulation on horizontal surfaces in interiors: Influence of foliage plants. Atmos. Environ. 30:25652568.

Lohr, V.I., C.H . Pearson-M ims, and G.K. Goodwin. 1996. Interior plants may improveworker productivity and reducestress in a windowless environment. J. Environ. H ort. 14:97-100.

M aas, J.B., J.K. Jayson, and D.A. Kleiber. 1974. Effects of spectral differences in illumination on fatigue. J. Appl. Psychol. 59:524-526.

Rautiala, S., S. H aatainen, H. Kallunki, L. Kujanpaa, S. Laitinen, A. M iihkinen, M. Reiman, and M. Seuri. 1999. D o plants in office have any effect on indoor air microorganisms? Proc. Indoor Air 2:704-709.

Rosenthal, N.E., D.A. Sack, J.C. Gillin, A.J . Lewy, F.K. Goodwin, Y. D avenport, P.S. M ueller, D.A. N ewsome, and T.A. Wehr. 1984. Seasonal affective disorder. A description of the syndrome and preliminary findings with light therapy. Arch. Gen. Psych. 41:72-80.

Skov, P., O . Valbjørn, and B.V. Pedersen. 1990. Influence of indoor climate on the sick building syndrome in an office environment. Scand. J. Work Environ. H ealth 16:363-371.

U Irich, R.S. 1979. Visual landscapes and psychological well-being. L andscape Res. 4:17-23.

U Irich, R.S. 1981. N atural versus urban scenes: Some psychophysiological effects. Environ. Behavior 13:523-556.

U Irich, R.S. 1984. View through a window may influence recovery from surgery. Science 224:420-421.

U Irich, R.S., O . L undèn, and J .L. Eltinge. 1993. Effects of exposure to nature and abstract pictures on patients recovering from open heart surgery. Psychophysiology 30:57.

U Irich, R.S. and R. Parsons. 1992. Influences of passive experiences with plants on individual well-being and health, p. 93105. In: D. Relf (ed.). Therole of horticulture in human well-being and social development. Timber Press, Portland, 0 re.

U Irich, R.S., R.F. Simons, B.D . Losito, E. Fiorito, M.A. M iles, and M.Zelson. 1991. Stress recovery during exposure to natural and urban environments. J. Environ. Psychol. 11:201-230.

Wolverton, B.C., A. Johnson, and K. Bounds. 1989. Interior landscape plants for indoor air pollution abatement. Final Report. NASA, John C. Stennis Space $C$ enter, $M$ iss. 